\title{
PENGARUH PENGUASAAN KOSAKATA DAN TATA BAHASA TERHADAP PEMAHAMAN MEMBACA TEKS NARASI BAHASA INGGRIS
}

\author{
Vickry Ramdhan \\ Program Studi Teknologi Informatika \\ Universitas Indraprasta PGRI \\ vickry.ramdhann@gmail.com
}

\begin{abstract}
Abstrak
Tujuan dari penelitian ini adalah untuk mengetahui pengaruh penguasaan kosakata terhadap pemahaman membaca teks narasi bahasa Inggris. Mengetahui pengaruh tata bahasa terhadap pemahaman membaca teks narasi bahasa Inggris. Selanjutnya untuk mengetahui pengaruh penguasaan kosakata dan tata bahasa secara bersama-sama terhadap Pemhaman membaca teks narasi bahasa Inggris. Metode penelitian yang digunakan adalah metode survei, sampel diambil sebanyak 30 siswa dengan teknik acak sederhana. Pengumpulan data menggunakan instrument: tes, analisis data menggunakan statistika deskriptif seperti mencari mean, median, modus, standar deviasi dan statika inpresial yaitu untuk mencari koefisien korelasi dengan uji t. Proses penelitian ini berlangsung hampir 1 bulan dimana peneliti melakukan tes langsung di kedua kelas tersebut. Penelitian ini dilakukan pada bulan Januari 2016. Hasil menunjukkan; 1) Terdapat pengaruh yang signifikan penguasaan kosakata dan penguasaan tata bahasa secara bersama-sama terhadap pemahaman membaca teks narasi. Hal ini dibuktikan dengan perolehan nilai Sig. $0,000<0,05$ dan $F_{h}=12,281$. Secara bersama-sama penguasaan kosakata dan penguasaan tata bahasa memberikan kontribusi sebesar 34,3\% terhadap variable pemahaman membaca teks narasi. 2) Terdapat pengaruh yang signifikan penguasaan kosakata terhadap pemahaman membaca teks narasi. Hal ini dibuktikan dengan perolehan nilai Sig. 0,010 $<0,05$ dan $t_{h}=3,349$. Variabel penguasaan kosakata memberikan kontribusi sebesar $21,89 \%$ dalam meningkatkan pemahaman membaca teks narasi. 3) Terdapat pengaruh yang signifikan penguasaan tata bahasa terhadap pemahaman membaca teks narasi. Hal ini dibuktikan dengan perolehan nilai Sig. $0,027<$ 0,05 dan $t_{h}=2,287$. Variabel penguasaan tata bahasa memberikan kontribusi sebesar $12,44 \%$ dalam meningkatkan pemahaman membaca teks narasi.
\end{abstract}

Kata Kunci: Penguasaan Kosakata, Tata Bahasa, Pemahaman Membaca Teks Narasi Bahasa Inggris

\begin{abstract}
The aim of this research is for knowing the effect of vocabulary mastery towards the understanding of narrative reading English text. Then, to know the effects of vocabulary and grammar mastery together towards the understanding of narrative reading English text. Survey method is used for this research methodology, sample is taken from 30 students by random sampling technique. Instruments that used to collect the data: test, data analysis using descriptive statistics to find mean, median, and modus, deviation standard, and impretial static to search for correlation coefficient with $T$ determination. These research processes take a month where the researcher gives the direct tests in both of classes. This research is done on January, 2016. Results showed; 1) there is significant effect of vocabulary and grammar mastery towards the understanding of narrative text English reading together. It is proven by Sig. 0,000<0,05 and $F h=12,281$. Vocabulary and grammar mastery togetherness give the contribution as much 34,3\% towards the understanding of narrative text reading. 2) There is significant effect of vocabulary mastery towards the understanding of narrative reading text. It is proven by Sig. 0,010<0,05 and th=3,349. The variable of vocabulary mastery gives the contribution as much $21,89 \%$ to increase the understanding of narrative text reading. 3) There is significant effect of grammar mastery towards the understanding of narrative reading text. It is proven by Sig. 0,027<0,05 and th=2,287. The variable of grammar mastery gives the contribution as much $12,44 \%$ to increase the understanding of narrative text reading.
\end{abstract}

Key words: vocabulary mastery, grammar, the understanding of narrative reading English text 


\section{PENDAHULUAN}

Bahasa mempunyai peranan yang penting dalam pengembangan aspek intelektual, sosial dan emosional siswa. Fungsi bahasa tidak hanya sebagai subyek atau sebuah mata pelajaran tetapi juga sebagai alat siswa untuk mengekspresikan ide atau pemikiran dan perasaan mereka dalam kehidupan sehari-hari baik di lingkungan masyarakat atau di lingkungan sekolah. Maka, setelah mempelajari bahasa, siswa diharapkan memiliki beberapa kemampuan khususnya kemampuan berbicara yang akan mampu membuat mereka berkomunikasi dengan baik dan benar. Terlebih, bahasa adalah sebuah sistem yang diciptakan oleh manusia untuk berkomunikasi (Kurikulum 2004:35). Definisi ini menunjukan bahwa semua orang membutuhkan bahasa untuk berkomunikasi dalam rangka penyampaian ide, gagasan serta perasaan mereka kepada lawan bicara.

Dalam mempelajari bahasa Inggris seseorang dituntut untuk menguasai beberapa keterampilan. Menurut Hoetomo MA (2005:531-532), "Keterampilan adalah kecakapan untuk menyelesaikan tugas." Pengertian tersebut menjelaskan bahwa segala hal yang kita kerjakan membutuhkan keterampilan. Begitu pun dengan mempelajari bahasa Inggris, siswa harus belajar bahasa Inggris dengan menyeimbangkan empat keterampilan berbahasa agar siswa dapat menyerap dan mengaplikasikan bahasa Inggris dengan mudah dalam kehidupan sehari-hari.

Di dalam pembelajaran bahasa Inggris di sebuah sekolah, para siswa harus mengerti empat elemen penting dalam pelajaran bahasa Inggris, ke empat elemen tersebut yaitu kemampuan menyimak, berbicara, membaca dan menulis. Di samping dalam menguasai kemampuan-kemampuan tersebut, mereka juga harus mengetahui aspek bahasa, seperti pengucapan, kosakata dan tata bahasa. Sayangnya, ini tidak mudah bagi para siswa untuk menguasai kemampuan tersebut, karena mereka akan mengalami berbagai hambatan di dalam penguasaan kemampuan dan aspek ini. Sebagai contoh, dalam kemampuan berbicara para siswa mungkin dihadapkan pada situasi di mana mereka mempunyai perbendaharaan kosakata yang minim, sehingga mereka kesulitan untuk berbicara dan secara otomatis mereka kesulitan menyampaikan ide atau gagasan serta pemikiran mereka. Selain itu mereka mungkin tidak mempunyai pengetahuan tentang tata bahasa. Hal-hal seperti ini akan menyebabkam rasa malu dan kurang percaya diri pada siswa tersebut.

Menyadari kenyataan pentingnya bahasa Inggris dimasa depan, maka pembelajaran bahasa Inggris sedini mungkin harus ditetapkan di sekolah-sekolah yang merupakan salah satu upaya peningkatan kompetensi individu dalam pembelajaran bahasa Inggris. Mengingat ke depan persaingan yang dihadapi dengan bangsa lain maka tamatan suatu sekolah selain harus mempunyai kompetensi produktif juga harus mempunyai kompetensi bahasa Inggris, karena bahasa Inggris merupakan bahasa pengantar yang dipakai secara international.

Kenyataan yang ada di dunia kerja, yaitu dunia usaha dan dunia industri, bahwa penggunaan bahasa Inggris bagi tenaga kerja bukan hanya untuk memahami petunjuk, membaca manual ataupun memahami instruksi penggunaan peralatan lainnya, namun lebih pada penggunaan untuk berkomunikasi lisan, dan untuk bisa berkomunikasi secara baik harus menguasai kosakata yang memadai pula. Belajar bahasa tidak akan terlepas dari belajar kosakata, penguasaan kosakata merupakan hal 
terpenting dalam keterampilan bahasa, tanpa penguasaan kosakata yang memadai, maka tujuan pembelajaran bahasa tidak akan tercapai, karena semakin banyak kosakata yang dimiliki seseorang semakin terampil pula dia berbahasa.

Penguasaan kosakata merupakan salah satu syarat utama yang menentukan keberhasilan seseorang terampil berbahasa, semakin kaya kosakata seseorang semakin besar seseorang kemungkinan untuk terampil berbahasa dan semakin mudah pula dia menyampaikan dan menerima informasi baik secara lisan, tulisan, maupun menggunakan tanda-tanda dan isyarat. Dalam hal ini Tarigan (1985:85), menjelaskan bahwa kosakata dapat meningkatkan pertumbuhan kegiatan menulis, berbicara, membaca, dan menyimak.

Kridalaksana (1993:127) mendefinisikan kosakata sebagai komponen bahasa yang memuat semua informasi tentang makna dan pemakaian dalam bahasa.

Sedangkan pelaksanaan pembelajaran bahasa Inggris yang selama ini di laksanakan masih belum merangsang siswa supaya aktif di dalam pembelajaran bahasa Inggris. Pembelajaran lebih banyak melatih siswa untuk melakukan latihan-latihan tertulis dan menghafalkan kata atau tata bahasa Inggris, bahkan ada siswa yang takut ketika ada pelajaran bahasa Inggris karena merasa tidak bisa, ada juga menjadi malas karena hanya di suruh membaca dan menterjemahkan, jadi siswa menjadi kurang aktif di dalam pembelajaran.

Sebenarnya, siswa belajar kosakata dan tata bahasa setiap hari, baik di dalam situasi kelas ataupun di luar. Akan tetapi, ada permasalahan yang terjadi, karena bahasa Inggris diletakkan sebagai bahasa asing oleh pemerintah, sehingga penguasaan kosakata dan tata bahasa tidak sesuai dengan yang diharapkan. Padahal menurut David (1995:118), "the enrichment of vocabulary is an important factor in the second language acquisition". Ahli lain yang menyatakan bahwa pentingnya kosakata di dalam pembelajaran bahasa adalah Byre (1980:156), dia menyatakan bahwa "vocabulary is the vital aspect of language". Ahli lain yang menyatakan tentang pentingnya kosakata adalah Tarigan. Dia berpendapat bahwa "penguasaan bahasa ditentukan oleh jumlah kosakata". Maka bisa disimpulkan bahwa dengan memiliki penguasaan kosakata dan tata bahasa yang baik, para pembelajar bahasa tidak akan kesulitan dalam proses belajar bahasa. Dengan kata lain dan dengan tidak menyampingkan pengucapan sebagai aspek bahasa, kosakata dan tata bahasa menjadi aspek yang penting di dalam pemerolehan suatu bahasa asing.

Dari penjelasan di atas, ada ketertarikan untuk melakukan penelitian yang berhubungan dengan kosakata, tata bahasa dan membaca. Sehingga memunculkan sebuah ide berupa judul tesis yang akan di lakukan penelitian seperti ini "Pengaruh penguasaan kosakata dan tata bahasa terhadap pemahaman membaca teks narasi”.

\section{METODE PENELITIAN}

Dalam Penelitian ini menggunakan metode survey untuk mengetahui pengaruh antara kosakata dan tata bahasa dengan pemahaman membaca teks narasi bahasa Inggris siswa kelas XI Sekolah Asy Syifa Depok. 


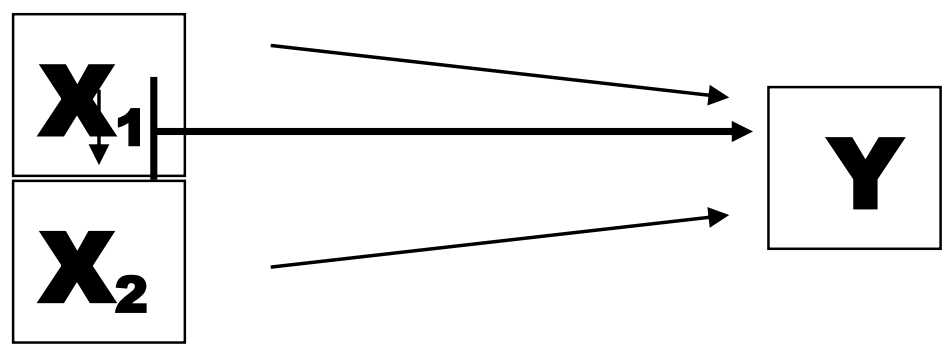

Gambar Desain Penelitian

X1: Penguasaan kosakata

$\mathrm{X} 2$ : Tata Bahasa

Y: Pemahaman membaca teks narasi

Menurut Kerlinger yang disunting oleh Ridwan (2005:49) mengatakan bahwa "penelitian survey adalah penelitian yang dilakukan pada populasi besar maupun kecil, tetapi data yang dipelajari adalah data yang diambil dari sampel populasi tersebut, sehingga ditemukan kejadian-kejadian relative, distribusi dan hubungan antara variabel".

Pendekatan yang digunakan adalah pendekatan kuantitatif, yaitu pendekatan yang memungkinkan dilakukan pencatatan dan analisi data hasil penelitian secara eksak dan menganalisis datanya menggunakan perhitungan statistik (Sugiyono, 2007: 7). Sedangkan analisis ini bertujuan untuk mengetahui hubungan antara tiga variabel yaitu variabel bebas $\mathrm{X} 1$ dan $\mathrm{X} 2$ dengan variabel terikat $\mathrm{Y}$. Bentuk hubungan yang diteliti adalah bentuk hubungan kausal, yaitu hubungan sebab akibat.

Dari penjelasan di atas, maka dapat diasumsikan bahwa kemampuan membaca siswa valid dan reliabel positif dan signifikan terhadap penguasaan kosakata dan tata bahasa Inggris siswa.

\section{HASIL DAN PEMBAHASAN}

\section{Deskripsi Data}

1. Data Pemahaman membaca teks narasi (Y)
Data pemahaman membaca teks narasi diperoleh dari nilai tes sebanyak 50 siswa yang menjadi sampel penelitian. Nilai yang di peroleh adalah terendah 55, tertinggi 95 , rata-rata sebesar 75,28 , median sebesar 75, modus sebesar 75 dan simpangan baku sebesar 9,920.

Bila dilihat dari hasil perhitungan di atas, maka bisa dikatakan bahwa pemahaman membaca teks narasi siswa SMK Swasta Depok tergolong cukup baik. Hal ini di indikasikan dengan perolehan nilai rata-rata sebesar 75,28.

2. Data Penguasaan kosakata siswa (X1)

Data penguasaan kosakata diperoleh dari nilai tes sebanyak 50 siswa yang menjadi sampel penelitian dihasilkan skor terendah 60 , skor tertinggi 95 , skor rerata sebesar 80,2 , median 80, modus sebesar 80 , dan simpangan baku sebesar 9,528.

Dari hasil perhitungan di atas, maka bisa dikatakan bahwa penguasaan kosakata siswa SMK Swasta Depok baik. Hal ini di indikasikan dengan perolehan skor rerata sebesar 80,2

3. Data Penguasaan tata bahasa (X2)

Data penguasaan tata bahasa diperoleh dari nilai tes sebanyak 50 siswa yang menjadi sampel penelitian dihasilkan nilai terendah 60 , skor 
tertinggi 95, skor rerata sebesar 78,6, median sebesar 80 , modus sebesar 80 dan simpangan baku sebesar 9,478.

Dari hasil perhitungan di atas, maka bisa dikatakan bahwa penguasaan tata bahasa siswa SMK Swasta Depok cukup baik. Hal ini di indikasikan dengan perolehan nilai rerata skor disiplin diri 78,6.

\section{Uji Hipotesis}

1. Pengaruh Penguasaan kosakata (X1) dan Penguasaan tata bahasa (X2) secara bersama-sama terhadap Pemahaman membaca teks narasi (Y)

Hipotesis yang diuji:

$H_{0}: \beta_{y 1}=\beta_{y 2}=0$

$H_{1}: \beta_{y 1} \neq 0, \beta_{y 2} \neq 0$

Artinya:

$\mathrm{H}_{0}$ : tidak terdapat pengaruh penguasaan kosakata dan penguasaan tata bahasa secara bersama-sama terhadap pemahaman membaca teks narasi

$\mathrm{H}_{1}$ : terdapat pengaruh penguasaan kosakata dan penguasaan tata bahasa secara bersama-sama terhadap pemahaman membaca teks narasi

Dari data diatas dinyatakan bahwa terdapat pengaruh yang signifikan penguasaan kosakata dan penguasaan tata bahasa secara bersama-sama terhadap pemahaman membaca teks narasi. Hal ini dibuktikan dengan perolehan nilai Sig. 0,000<0,05 dan $F_{h}=12,281$.

Sementara itu, persamaan garis regresi ganda dapat dinyatakan dengan $\widehat{Y}=16,430+0,439 \mathrm{X} 1+$ $0,301 \quad \mathrm{X} 2$. Hal ini memiliki pengertian bahwa kenaikan satu skor variable penguasaan kosakata dan penguasaan tata bahasa memberikan kontribusi sebesar 0,439 oleh X1 dan
0,301 oleh X2 terhadap variable pemahaman membaca teks narasi. Dari tabel 4.9 juga dapat menjelaskan bahwa secara bersamasama variable penguasaan kosakata dan penguasaan tata bahasa memberikan kontribusi sebesar 34,3 $\%$ terhadap variable pemahaman membaca teks narasi.

2. Pengaruh Penguasaan kosakata $\left(X_{1}\right)$ terhadap Pemahaman membaca teks narasi (Y)

Hipotesis yang diuji:

$H_{0}: \beta_{y 1}=0$

$H_{1}: \beta_{y 1} \neq 0$

Artinya:

$\mathrm{H}_{0}$ : tidak terdapat pengaruh penguasaan kosakata terhadap pemahaman membaca teks narasi

$\mathrm{H}_{1}$ : terdapat pengaruh penguasaan kosakata terhadap pemahaman membaca teks narasi

Dari data di atas dapat dinyatakan bahwa terdapat pengaruh yang signifikan penguasaan kosakata terhadap pemahaman membaca teks narasi. Hal ini dibuktikan dengan perolehan nilai Sig. $0,010<0,05$ dan $t_{\mathrm{h}}=3,349$.

Adapun kontribusi variabel penguasaan kosakata terhadap Pemahaman membaca teks narasi dapat dinyatakan dengan rumus:

$\mathrm{KD}=$ Nilai $\beta_{x 1 y} \times$ Nilai Korelasi Pasialnya $\left(r_{x 1 y}\right) \times 100 \%$

$$
\mathrm{KD}=0,421 \times 0,520 \times 100 \%=21,89
$$
$\%$

Dari hasil perhitungan di atas dapat dinyatakan bahwa kontribusi penguasaan kosakata dalam meningkatkan pemahaman membaca teks narasi sebesar $21,89 \%$

3. Pengaruh Penguasaan tata bahasa (X2) terhadap Pemahaman membaca teks narasi (Y) 
Hipotesis yang diuji:

$H_{0}: \beta_{y 1}=0$

$H_{1}: \beta_{y 1} \neq 0$

Artinya:

$\mathrm{H}_{0}$ : tidak terdapat pengaruh penguasaan tata bahasa terhadap pemahaman membaca teks narasi

$\mathrm{H}_{1}$ : terdapat pengaruh penguasaan tata bahasa terhadap pemahaman membaca teks narasi

Dari data diatas dapat dinyatakan bahwa terdapat pengaruh yang signifikan penguasaan tata bahasa terhadap pemahaman membaca teks narasi. Hal ini dibuktikan dengan perolehan nilai Sig. 0,027 $<0,05$ dan $t_{h}=2,287$.

Adapun kontribusi variabel penguasaan tata bahasa terhadap pemahaman membaca teks narasi dapat dinyatakan dengan rumus:

$\mathrm{KD}=$ Nilai $\beta_{x 2 y} \times \mathrm{x}$ Nilai Korelasi Pasialnya $\left(r_{x 2 y}\right) \times 100 \%$

$\mathrm{KD}=0,288 \times 0,432 \times 100 \%=12,44$ $\%$

Dari hasil perhitungan di atas dapat dinyatakan bahwa kontribusi penguasaan tata bahasa dalam meningkatkan pemahaman membaca teks narasi sebesar $12,44 \%$.

\section{SIMPULAN}

1. Pengaruh penguasaan kosakata (X1) dan penguasaan tata bahasa (X2) secara bersama-sama terhadap pemahaman membaca teks narasi (Y)

Hasil penelitian di atas menyimpulkan bahwa penguasaan kosakata dan penguasaan tata bahasa secara bersama-sama telah memberikan pengaruh positif terhadap peningkatan pemahaman membaca teks narasi siswa. Hal ini mengandung arti bahwa penguasaan kosakata dan penguasaan tata bahasa telah memberikan pengaruh yang signifikan terhadap peningkatan pemahaman membaca teks narasi siswa SMK Swasta Depok.

2. Pengaruh penguasaan kosakata (X1) terhadap pemahaman membaca teks narasi $(\mathrm{Y})$

Hasil penelitian di atas menyimpulkan bahwa penguasaan kosakata telah memberikan pengaruh positif terhadap peningkatan pemahaman membaca teks narasi. Hal ini mengandung arti bahwa penguasaan kosakata siswa memberikan pengaruh yang cukup signifikan terhadap peningkatan pemahaman membaca teks narasi.

3. Pengaruh Penguasaan tata bahasa (X2) terhadap Pemahaman membaca teks narasi $(\mathrm{Y})$

Dari hasil penelitian dan teori yang ada dapat disimpulkan bahwa penguasaan tata bahasa telah memberikan pengaruh positif terhadap peningkatan Pemahaman membaca teks narasi. Artinya, penguasaan tata bahasa yang tinggi telah memberikan pengaruh yang signifikan terhadap peningkatan pemahaman membaca teks narasi.

Para guru bahasa Inggris hendaknya selalu mengupayakan agar siswa memahami dan menguasai kosakata bahasa Inggris yang sebanyak-banyaknya dan pengetahuan tata bahasa Inggris yang mumpuni agar siswa mempunyai kemampuan yang tinggi dalam memahami teks bahasa Inggris dan guru bahasa Inggris hendaknya juga membekali diri serta meningkatkan kompetensi diri dengan penguasaan kosakata bahasa Inggris yang sebanyakbanyaknya dan tata bahasa yang baik agar lebih siap dalam memberikan pembelajaran da pembekalan kepada siswa. 


\section{DAFTAR PUSTAKA}

Byre. 1980. Guidelines for Vocabulary Teaching, Singapure: RELC Editorial Committee.

Hughes, A. 1980. Testing for Language Teacher, Great Britain: Cambrige University Press.

Madson, S Harold. 1983. Techniques in Testing. New York: Oxford University Press.
Sudijono, A. 1995. Pengantar Evaluasi Pendidikan. Jakarta: Kharisma putra utama offset.

Sugiyono. 2007. Statistika Untuk Penelitian. Bandung: Alfabeta

Tarigan, H.G. 1983. Membaca Sebagai Suatu Keterampilan Berbahasa. Bandung: Angkasa. 